\title{
Study on Demethoxycurcumin as a promising approach to reverse methicillin-resistance of Staphylococcus aureus
}

Qian-Qian Li

Wonkwang Oriental Medicines Research Institute

Ok-Hwa Kang

Wonkwang Oriental Medicines Research Institute

Dong-Yeul Kwon ( $\sim$ sssimi@wku.ac.kr)

Wonkwang Oriental Medicines Research Institute

\section{Research Article}

Keywords: Methicillin-resistant Staphylococcus aureus, MRSA, Demethoxycurcumin, Anti-bacterial activity, Synergistic effect, PBP2a, $\beta$-lactam antibiotic

Posted Date: February 26th, 2021

DOl: https://doi.org/10.21203/rs.3.rs-200260/v1

License: (c) (i) This work is licensed under a Creative Commons Attribution 4.0 International License. Read Full License 


\section{Abstract \\ Background}

Methicillin-resistant Staphylococcus aureus (MRSA) has always been a thorny pathogen, posing serious threat to public health. Current treatment resort for MRSA infections is still scarce. Research on phytochemical component that can replace antibiotics with limited efficacy may be an innovative method to solve intractable MRSA infections. The present study was devoted to investigating the antibacterial activity of the natural compound demethoxycurcumin (DMC) against MRSA and exploring its possible mechanism for eliminating MRSA resistance.

\section{Methods}

The present study determined minimum inhibitory concentrations (MICs) of DMC, oxacillin, ampicillin and gentamicin against MRSA strains by the broth microdilution method. The synergistic effects of DMC and antibiotics were investigated by the checkerboard method and the time-kill assay. The membranepermeabilizing agents and ATP synthase inhibitors were employed to explore their impact on the antibacterial ability of DMC. Western blot analysis and qRT-PCR were performed to detect the proteins and genes related to drug resistance and $S$. aureus exotoxins.

\section{Results}

The MIC of DMC against MRSA is $62.5 \mu \mathrm{g} / \mathrm{ml}$ by broth microdilution method. The synergy between DMC and gentamicin was confirmed by checkerboard method and time-kill assay. When ATP synthase inhibitors blocked the metabolic ability of bacteria, the antibacterial effect of DMC was enhanced. The production of penicillin-binding protein 2a (PBP2a) protein and related genes were reduced by DMC at sub-inhibitory concentrations. In addition, DMC hindered the translation of staphylococcal enterotoxin and the transcription of related gene.

\section{Conclusions}

Based on our results, DMC has a significant inhibitory effect on the vitality of MRSA, and it can be inferred that the mechanism by which DMC reverses MRSA resistance is related to the ability of DMC to block resistance determinants (PBP2a and $\beta$-lactamase) and $S$. aureus exotoxin. This study provides experimental evidences that $\mathrm{DMC}$ has the potential to be a candidate substance for the treatment of MRSA infections.

\section{Background}


Staphylococcus (S.) aureus is a virulent opportunistic pathogen that can cause manifold infections, including skin and soft-tissue infections, bloodstream infections, toxin-mediated syndromes and lifethreatening diseases [1]. As one of the "ESKAPE" organisms, S. aureus is triggering increasing menace worldwide because it can cause a variety of serious nosocomial infections [2]. Methicillin-sensitive $S$. aureus (MSSA) and methicillin-resistant $S$. aureus (MRSA) are the two main types of infections caused by $S$. aureus [3]. Researchers have been committed to studying antibiotics to combat the invasion of $S$. aureus, however, the emergence of MRSA limits the usage of antibiotics, making the treatment of $S$. aureus infections more complicated [4, 5]. MRSA is a common Gram-positive bacteria causing infections in both the hospital and the community, and can be isolated from hospitalized patients and outpatient settings [6]. Since it was first identified as a hospital-acquired pathogen in 1961, MRSA has become the major cause of death in the ICU [7]. In the 1990s, community-acquired MRSA strains appeared in young, healthy individuals who lacked the classic risk factors that have previously been in contact with healthcare institutions [8]. The resistance of MRSA to $\beta$-lactam antibiotics is inducible, which is the result of the expression of two resistant enzymes, $\beta$-lactamase and penicillin-binding protein (PBP) 2a transpeptidase [9].

The $\beta$-lactam antibiotics have long been widely used as the cornerstone for the treatment of infections caused by $S$. aureus [10]. $\beta$-Lactam antibiotics, including penicillin, cephalosporin, carbapenem and monobactam, are the most commonly used antibiotics, which account for more than half of the antibiotics prescribed in clinical settings $[11,12]$. The $\beta$-lactam antibiotics are believed to function by interfering with the bacterial cell wall biosynthesis [13]. Since the cell wall peptidoglycan layers of grampositive bacteria is thicker than that of gram-negative bacteria [14], the $\beta$-lactam antibiotics generally have higher inhibitory activity against gram-positive bacteria. Many gram-negative bacteria produce $\beta$ lactamase to hydrolyze the $\beta$-lactam bond of antibiotics and render them ineffective, which is the internal mechanism of Gram-negative bacteria against $\beta$-lactam antibiotics [15].

The excessive use of $\beta$-lactam antibiotics in clinical treatment and animal husbandry has led to the increasing prevalence of antibiotic-resistant $S$. aureus, which is a worrying global clinical problem [16]. Penicillin-binding proteins (PBPs) are essential membrane-bound proteins for the biosynthesis of bacterial cell wall. The $\beta$-lactam antibiotics are known to acylate the transpeptidase domain of PBPs in $S$. aureus [17]. The irreversible binding of $\beta$-lactam antibiotics to the active site of PBPs makes them chemically inert and prevents peptidoglycan cross-linking, thereby inhibiting bacterial cell wall biosynthesis and eventually causing cell lysis and death [18]. However, many $S$. aureus have developed resistance to $\beta$-lactam antibiotics due to the acquisition of the mecA gene [19]. The gene $m e c A$ is harboured on the mobile genetic element so-called staphylococcal chromosomal cassette mec (SCCmec) and encodes the penicillin binding protein 2a (PBP2a), an alternative transpeptidase with low affinity for virtually all $\beta$-lactam antibiotics $[20,21]$. When the native PBPs are inhibited by binding $\beta$-lactam antibiotics, the function of PBP2a can replace the activity of PBPs to continue catalyzing the biosynthesis of the cell wall peptidoglycan $[22,23]$. Thus, the function of PBP2a allows the normal growth and viability of $S$. aureus even in the presence of high concentrations of $\beta$-lactam antibiotics that inhibit natural PBPs [24]. In addition, more than $90 \%$ of $S$. aureus also produce $\beta$-lactamase encoded by 
the blaZ gene, which cleaves the $\beta$-lactam ring and causes hydrolysis and inactivation of the $\beta$-lactam antibiotic [25].

Conventional medicine plays a critical role in prevention and treatment of various diseases and conditions for centuries [26]. Therefore, the exploration of antimicrobials extracted from natural herbs as an alternative substance for antibiotics is highly anticipated. Turmeric, the rhizomatous plant belonging to Curcuma longa Linn (Zingiberaceae), has long been used as a natural medicine to treat various diseases [27]. A large repertoire of evaluations have been conducted on the medicinal value of turmeric, and studies have reported that turmeric extract possesses manifold pharmacological activities, such as anti-inflammatory, antioxidant, anti-tumor and antimicrobial activities [28, 29]. Turmeric contains curcumin (CM), demethoxycurcumin (DMC) and bisdemethoxycurcumin (BDMC) as major curcuminoids [30].

Curcumin is a well-known curcuminoid that has obtained more attention and research, but due to its low aqueous solubility, most of $\mathrm{CM}$ is unabsorbed after oral administration. The present study focused on DMC (Fig. 1), which is an analog of CM chemically without a methoxy group directly linked to the benzene ring [31]. Accordingly, this more stable structure makes DMC exhibit better stable activity and aqueous solubility than $\mathrm{CM}$ at physiological $\mathrm{pH}$. It has been reported that $\mathrm{DMC}$ has a veriety of pharmacological activities, including anti-inflammatory, antihypertensive, neuroprotective, antimicrobial, antifungal, antimalarial and vasodilatory properties [32]. However, the study of DMC in the treatment of MRSA infection is not comprehensive. Thus, we conducted a series of in vitro study to investigate whether DMC has the therapeutic properties of $\beta$-lactamase inhibitor or inhibitor of PBP2a in the treatment of MRSA infections.

The present study focused on exploring the potential of the natural curcuminoid DMC as a novel antibacterial agent, aimed to investigate the sensitivity of MRSA to DMC in vitro, elucidate the possible pathogenic mechanism of DMC inhibiting the growth of MRSA, and evaluate the synergistic or alternative potential of DMC for $\beta$-lactam antibiotics.

\section{Methods}

\section{Bacterial strains and growth conditions}

ATCC 33591 standard MRSA strain and ATCC 25923 MSSA strain were purchased from the American Type Culture Collection (Manassas, VA, USA). CCARM 3090, 3091, 3095 and 3102 strains were provided by the Culture Collection of Antimicrobial Resistant Microbes (National Research Resource Bank, Seoul, Korea). And the remaining two clinical MRSA isolates (DPS-1 and 2) were collected from two different patients at the Department of Plastic Surgery, Wonkwang University Hospital (Iksan, Korea). All test bacteria were incubated on Mueller-Hinton agar (MHA) or Brain Heart Infusion agar (BHIA) and suspended in Mueller-Hinton broth (MHB) or Brain Heart Infusion broth (BHIB), grown at $37^{\circ} \mathrm{C}$. All strains were stored in $30 \%$ glycerol and frozen at $-80^{\circ} \mathrm{C}$. 


\section{Reagents and instruments}

Mueller-Hinton agar, Brain Heart Infusion agar, Mueller-Hinton broth, Brain Heart Infusion broth and skim milk were obtained from Becton, Dickinson and Company (Sparks, MD, USA). Glycerol was purchased from Junsei Chemical Co., Ltd. (Tokyo, Japan). Demethoxycurcumin (DMC), thiazolyl blue tetrazolium bromide (MTT), triton X-100 (TX-100), tris (hydroxymethy) aminomethane ACS reagent (Tris), N, N'dicyclohexylcarbodiimide (DCCD), sodium azide $\left(\mathrm{NaN}_{3}\right)$, oxacillin (OXA), ampicillin sodium salt (AMP) and gentamicin sulfate (GEN) were purchased from Sigma-Aldrich Co. (St. Louis, MO, USA). SMART ${ }^{\text {TM }}$ bacterial protein extraction solution was purchased from Intron Biotechnology Inc. (Seongnam, Korea). Mouse anti-PBP2a antibody was purchased from DiNonA Inc. (Seoul, Korea). Polyclonal rabbit antiStaphylococcus Enterotoxin B antibody ab 15898 was purchased from Abcam (UK). Mouse anti-GAPDH antibody was purchased from Santa Cruz (Dallas, TX, USA). E.Z.N.A. ${ }^{\circledR}$ bacterial RNA kit was purchased from OMEGA Bio-Tek (Norcross GA, USA).

\section{Determination of minimal inhibitory concentration}

The present study tested the susceptibility of MSSA and MRSA strains by measuring the minimal inhibitory concentration (MIC). The MIC values of DMC and the $\beta$-lactam antibiotics OXA, AMP and GEN against MRSA and MSSA were determined via broth microdilution assay. A series of 2-fold dilutions with an initial concentration of $1000 \mu \mathrm{g} / \mathrm{ml}$ of DMC were prepared in MHB and BHIB using a 96-well microplate. As for the three antibiotics, the initial concentration was $2000 \mu \mathrm{g} / \mathrm{ml}$ respectively. The inocula were adjusted to $1.5 \times 10^{6} \mathrm{CFU} / \mathrm{ml}$ (colony-forming unit). After incubating for $24 \mathrm{~h}$ at $37^{\circ} \mathrm{C}$, added MTT reagent and continued incubating for $30 \mathrm{~min}$. The yellowish MTT solution was reduced to a dark blue formazan product by the mitochondrial dehydrogenases of living cells. The color depth is highly positively correlated with the number of live bacteria, which can visually display the minimum inhibitory concentrations.

\section{Determination of the in vitro effects of combinations of DMC and antibiotics}

One approach to treat MRSA infections is to combine existing $\beta$-lactam antibiotics with DMC. Thus, the present study investigated the synergism of DMC with OXA, AMP and GEN using checkerboard dilution test. Mix the serial 2-fold dilutions of DMC with different gradient concentrations of OXA, AMP and GEN into a 96-well plate. The inocula were adjusted to $1.5 \times 10^{6} \mathrm{CFU} / \mathrm{ml}$ and incubated at $37^{\circ} \mathrm{C}$ for $24 \mathrm{~h}$. The synergistic interaction between the drugs was quantified by fractional inhibitory concentration index $(\mathrm{FICl})$, which was calculated using the following formula: $\mathrm{FICl}=[\mathrm{A}] / \mathrm{MICA}+[\mathrm{B}] / \mathrm{MICB}$, where $[\mathrm{A}]$ and $[\mathrm{B}]$ represent the MIC of drug A and B in combination, respectively; MICA and MICB refer to MIC values of drug $A$ and $B$ alone, respectively. The $\mathrm{FICl}$ is interpreted as the following: $<0.5$, synergy; $0.5-0.75$, partial synergy; 0.75-1, additive effect; $1-4$, no effect; > 4, antagonism.

\section{Time-kill assay}


In order to determine the synergistic effect from the survival curve of bacteria, the standard strain ATCC 33591 and clinical strain DPS-2 were used to conduct experiments, and three treatment modes (DMC alone, GEN alone and GEN combined with DMC) were designed to compare the antibacterial effects with the control (no drug). The inocula were diluted to $1.5 \times 10^{6} \mathrm{CFU} / \mathrm{ml}$ and incubated at $37^{\circ} \mathrm{C}$. At five different time intervals $(0,4,8,16$ and $24 \mathrm{~h})$, the surviving bacteria were properly diluted and inoculated on the plate. After incubation at $37^{\circ} \mathrm{C}$ for 24 hours, counted the colonies on the plate. Then the number of viable bacteria was calculated according to the dilution ratio, and the growth curve was drawn.

\section{Determination of the in vitro effects of DMC on membrane-permeabilizing agents andATPsynthase inhibitors}

In order to explore whether the antibacterial effect of DMC can be enhanced by increasing membrane permeability or decreasing level of Adenosine triphosphate (ATP), the sensitivity of MRSA to DMC was determined in the presence of detergents and ATPase inhibitors. In this study, TX-100 and Tris were used as membrane-permeabilizing agents, and DCCD and $\mathrm{NaN}_{3}$ were used as inhibitor of $\mathrm{F}_{0} \mathrm{~F}_{1}$-ATP synthase. According to the checkerboard dilution test, the serial 2-fold dilutions of DMC dilutions and different gradient concentrations of TX-100, Tris, DCCD and $\mathrm{NaN}_{3}$ were mixed into a 96-well plate. Adjusted the bacteria to $1.5 \times 10^{6} \mathrm{CFU} / \mathrm{ml}$ and incubated at $37^{\circ} \mathrm{C}$ for $24 \mathrm{~h}$. The results were read at $\mathrm{OD}_{600 \mathrm{~nm}}$.

\section{Western blot analysis}

The western blot assay was performed according to the manufacturer's instructions to analyze protein translation levels. The MRSA (ATCC 33591) suspensions $\left(\mathrm{OD}_{600 \mathrm{~nm}}\right.$ value of 0.7$)$ were treated with graded sub-inhibitory concentrations of DMC and GEN. After shaking culture, the bacterial cells were harvested and suspended in bacterial protein extraction solution. Soluble protein was obtained by centrifuging the bacterial lysates at $13000 \mathrm{rpm}$ for 10 minutes. Sodium dodecyl sulfate-polyacrylamide gel electrophoresis (SDS-PAGE) was performed to separate denatured protein $(20 \mu \mathrm{l})$. The electrophoresed gels were transferred onto polyvinylidene difluoride (PVDF) blottong membranes. The membranes were blocked in $5 \%$ skim milk for $2 \mathrm{~h}$, and then incubated with first antibody (anti-PBP2a and anti-SEB) overnight at $4^{\circ} \mathrm{C}$. After incubation with secondary antibody for $1 \mathrm{~h}$, the immunoreative proteins were detected by TOPview ${ }^{\mathrm{TM}}$ ECL Femto Western Substrate (Enzynomics, Korea). ImageQuant LAS-4000 mini chemical luminescent imager (GE Healthcare Life, Korea) was used to visualize the immunoreactive protein bands of membranes.

\section{Quantitative reverse transcription polymerase chain reaction (qRT-PCR)}

The qRT-PCR was performed according to the manufacturer's instructions to analyze mRNA transcription levels. The ATCC 33591 strain was grown at an $\mathrm{OD}_{600 \mathrm{~nm}}$ of $0.7 \mathrm{in} \mathrm{MHB}$ and treated with sub-inhibitory concentrations of DMC and GEN. After shaking culture, centrifuged at $13000 \mathrm{rpm}$ for $10 \mathrm{~min}$ to pellet bacterial cells. Total RNA was isolated using the E.Z.N.A. ${ }^{\circledR}$ bacterial RNA kit according to the manufacturer's protocol. The mRNA purity were evaluated by measuring the absorbance ratio at $260 \mathrm{~nm}$ 
and 280nm using a Nanodrop spectrophotometer (Bio-Tek, Winooski, VT, USA). The QuantiTect reverse transcription kit (Qiagen, Seoul, Korea) was used to synthesize the complementary DNA (cDNA) according to the manufacturer's protocol. Mixed Power SYBR ${ }^{\circledR}$ Green PCR master mix (Applied Biosystems, Foster City, CA, USA), primers and cDNA. The qRT-PCR was run to synthesize DNA template using the StepOnePlus real-time PCR system (Applied Biosystems, France). The primer sequences are presented in Table 1.

Table 1 Sequences of oligonucleotide primers designed for qRT-PCR

\begin{tabular}{|ll|}
\hline Gene & Primer sequence \\
mecA & \\
\hline Forward & 5'- GCAATCGCTAAAGAACTAAG -3' \\
\hline Reverse & 5'-AATGGGACCAACATAACCTA -3' \\
\hline MecR1 & \\
\hline Forward & 5'-ACACGACTTCTTCGGTTAG -3' \\
\hline Reverse & 5'-GTACAATTTGGGATTTCACT -3' \\
\hline blaZ & \\
\hline Forward & 5'-AGAGATTTGCCTATGCTTCA -3' \\
\hline Reverse & 5'-AGTATCTCCGCTTTTATTATTT -3' \\
\hline blaR1 & \\
\hline Forward & 5'-ACAATGAAGTAGAAGCCGATAGAT -3' \\
\hline Reverse & 5'-GTCGGTCAAGTCCAAACA -3' \\
\hline sea & \\
\hline Forward & 5'-ATGGTGCTTATTATGGTTATC-3' \\
\hline Reverse & 5'-CGTTTCCAAAGGTACTGTATT-3' \\
\hline 16S RNA & \\
\hline Forward & 5'-ACTCCTACGGGAGGCAGCAG -3' \\
\hline Reverse & 5'-ATTACCGCGGCTGCTGG -3' \\
\hline
\end{tabular}

\section{Statistical analysis}

All data were expressed as the mean \pm standard deviation (SD) of triplicate tests. The statistical differences between groups were determined with one-way analysis of variance (ANOVA) using statistical software (IBM SPSS version 24). Multiple mean comparisons between treatments were performed using 
Duncan's multiple range test (DMRT). Different letters denote statistical differences between different groups $(p<0.05)$, while the same letters mean no significant differences $(p>0.05)$.

\section{Results}

\section{The minimum inhibitory concentration (MIC) of DMC and $\beta$-lactam antibiotics}

We initially used the MTT assay to detect the MIC of $\beta$-lactam antibiotic OXA, AMP, GEN and curcuminoid DMC. The MIC values of antibiotics and DMC against eight $S$. aureus strains are presented in Table 2 . According to the results of MIC values, all three antibiotics showed a significant inhibitory effect on MSSA (ATCC 25923). However, the concentration of OXA required for complete inhibition of seven MRSA strains ranged from 0.9 to $1000 \mu \mathrm{g} / \mathrm{ml}$, the MIC value of AMP against MRSA ranged from 1.9 to 125 $\mu \mathrm{g} / \mathrm{ml}$, and the MIC value of GEN against MRSA was 7.8 to $2000 \mu \mathrm{g} / \mathrm{ml}$. The high MIC values of $\beta$-lactam antibiotics confirmed the resistance of MRSA. We found that DMC was able to inhibit the growth of MRSA and displayed a MIC of $62.5 \mu \mathrm{g} / \mathrm{ml}$ for each $S$. aureus strain. The results showed that DMC has the ability to prevent MRSA from growth and suggested the potential of DMC to be further studied as an antibacterial agent.

Table 2 Minimum inhibitory concentration (MIC) of oxacillin (OXA), ampicillin (AMP), gentamicin (GEN) and demethoxycurcumin (DMC) against eight $S$. aureus strains

\begin{tabular}{|c|c|c|c|c|}
\hline Strains & $\mathrm{MIC}(\mu \mathrm{g} / \mathrm{ml})$ & & & \\
\hline OXA & AMP & GEN & DMC & \\
\hline ATCC 25923 & 0.9 & 0.9 & 0.9 & 62.5 \\
\hline ATCC 33591 & 125 & 125 & 7.8 & 62.5 \\
\hline DPS-1 & 62.5 & 62.5 & 125 & 62.5 \\
\hline DPS-2 & 0.9 & 1.9 & 125 & 62.5 \\
\hline CCARM 3090 & 250 & 31.25 & 125 & 62.5 \\
\hline CCARM 3091 & 1,000 & 62.5 & 2,000 & 62.5 \\
\hline CCARM 3095 & 500 & 31.25 & 250 & 62.5 \\
\hline CCARM 3102 & 250 & 62.5 & 500 & 62.5 \\
\hline
\end{tabular}

Values are means of three independent experiments

\section{Synergistic effects of DMC and antibiotics based on FICI}

Combining plant extracts with antibiotics is an empirical strategy to overcome the resistance of bacteria [33]. This study explored the synergistic antibacterial effect between plant extracts and antibiotics by 
combining curcuminoid DMC with the existing $\beta$-lactam antibiotics OXA, AMP and GEN. As shown in Table 3, DMC was able to reduce the MIC of GEN against seven MRSA strains by 4 to 16 fold. Compared with GEN alone, higher antibacterial activity with the lower MIC was observed when GEN was co-treated with DMC, which indicated that the presence of DMC enhanced the effectiveness of GEN. This results demonstrated that combining DMC with GEN at sub-MIC concentrations obviously increased the susceptibility of MRSA to GEN. However, there is no synergy between DMC and OXA. Similarly, the sensitivity of MRSA to AMP is not enhanced by the addition of DMC. The results regarding OXA and AMP were not shown in the current context.

Table 3 Minimum inhibitory concentration (MIC) and fractional inhibitory concentration index (FICl) of demethoxycurcumin (DMC) and gentamicin (GEN) against seven MRSA strains

\begin{tabular}{|c|c|c|c|c|c|}
\hline Strains & Agent & $\operatorname{MIC}(\mu \mathrm{g} / \mathrm{ml})$ & $\mathrm{FICl}$ & Outcome & \\
\hline Alone & Combination & & & & \\
\hline ATCC 33591 & DMC & 62.5 & 3.9 & 0.306 & synergy \\
\hline GEN & 7.8 & 1.9 & & & \\
\hline DPS-1 & DMC & 62.5 & 7.8 & 0.3748 & synergy \\
\hline GEN & 125 & 31.25 & & & \\
\hline DPS-2 & DMC & 62.5 & 7.8 & 0.2496 & synergy \\
\hline GEN & 125 & 15.6 & & & \\
\hline CCARM 3090 & DMC & 62.5 & 7.8 & 0.3748 & synergy \\
\hline GEN & 125 & 31.25 & & & \\
\hline CCARM 3091 & DMC & 62.5 & 7.8 & 0.3748 & synergy \\
\hline GEN & 2,000 & 500 & & & \\
\hline CCARM 3095 & DMC & 62.5 & 15.6 & 0.3746 & synergy \\
\hline GEN & 250 & 31.25 & & & \\
\hline CCARM 3102 & DMC & 62.5 & 3.9 & 0.3124 & synergy \\
\hline GEN & 500 & 125 & & & \\
\hline
\end{tabular}

Values are means of three independent experiments. Index interpretation: $<0.5$, synergy; $0.5-0.75$, partial synergy; $0.75-1$, additive effect; $1-4$, no effect; > 4, antagonism

\section{Time-kill assay}

The kill kinetics of antimicrobial activity provides more accurate description of antimicrobial agents, in contrast to the MIC assay [34]. Based on FICI, Fig. 2 depicted the synergism of DMC and GEN on standard 
MRSA strains (ATCC 33591) and clinically isolated strains (DPS-2) as the logarithm of the number of viable bacteria colonies at different time intervals. The results indicated that the treatment of DMC or GEN alone did not prevent bacterial growth significantly. After $24 \mathrm{~h}$ of incubation, the number of viable bacteria was the same as that of the control group without drug treatment, indicating that DMC and GEN almost lost their efficacy. However, the co-treatment of DMC and GEN at sub-MIC concentrations showed obvious bactericidal activity on both standard strains and clinical strains. It is worth mentioning that the standard strains showed stronger sensitivity to the combined use of DMC and GEN, so that there were no surviving bacteria after $16 \mathrm{~h}$ of culture. In brief, compared with other groups, the combination group showed the opposite growth trend, which indicates that the combined treatment at sub-MIC concentrations triggered a synergistic effect. The results of the time-kill assay further confirmed the medicinal value of DMC as an antibacterial agent, and suggested that DMC can be used as an auxiliary drug to treat MRSA infections.

\section{Antibacterial activity with membrane permeability or ATPsynthase inhibitor}

In order to fully understand the anti-MRSA ability of DMC, this study observed the antibacterial ability of DMC under conditions of increased cell membrane permeability or decreased ATP levels. TX-100 and Tris are bacterial membrane-binding agents used to regulate the permeability of bacterial cell membrane [35]. However, according to our experimental results, in the presence of TX-100 or Tris, DMC did not show a stronger inhibitory effect on the growth of MRSA (results not shown). $\mathrm{NaN}_{3}$ and DCCD are used as inhibitors of $F_{0} F_{1}$-ATP synthase to impede ATP-binding cassette transporters (ABC transporters) by blocking the proton translocation in $F_{0}$ domain of $F_{0} F_{1}$-ATP synthase [36, 37]. According to Fig. 3 , in the presence of $15.625 \mu \mathrm{g} / \mathrm{ml}(1 / 4 \mathrm{MIC})$ DMC, $25 \mu \mathrm{g} / \mathrm{ml} \mathrm{DCCD}$ or $125 \mu \mathrm{g} / \mathrm{ml} \mathrm{NaN} \mathrm{N}_{3}$ alone, MRSA maintained its viability. However, when DCCD or $\mathrm{NaN}_{3}$ blocked the activity of multidrug resistance efflux pumps [38], the $\mathrm{OD}_{600 \mathrm{~nm}}$ value decreased to $31.6 \%$ and $38.9 \%$, respectively, indicating that the sensitivity of MRSA to DMC is increased upon treatment with ATP synthase inhibitor. This results indicated that the reduction of metabolic capacity can elevate the anti-MRSA ability of DMC.

\section{The inhibitory effect of DMC on the expression of PBP2a protein and related gene in MRSA}

We hypothesize that the reversal mechanism of DMC on MRSA resistance is related to the variation of drug-resistant proteins and related genes. Given that PBP2a is a critical determinant of MRSA resistance mechanism, the present study analyzed the ability of DMC to reverse MRSA resistance by detecting the protein expression of PBP2a. According to Fig. 4, compared with the untreated control group, DMC substanitially inhibited the translation of PBP2a protein at a sub-inhibitory concentration, and antibacterial effect of DMC was obviously stronger than GEN. Since the translation of PBP2a is the result of triggering the transcription of $m e c A$, the current research also analyzed the mechanism of DMC against MRSA in terms of detecting the mec operon gene encoding PBP2a. Fig.5a illustrated that the inhibitory effect of DMC on mec gene complex at sub-inhibitory concentration was significantly higher than that of the control group without drug treatment and the GEN treatment group, and the higher the concentration of DMC, the greater its usefulness in attenuating bacterial viability. In addition, our research 
also reinforced the notion that DMC has the potential to develop into $\beta$-lactamase inhibitors by detecting the transcription of the bla gene complex. As shown in Fig. 5b, DMC apparently hindered the expression of bla operon gene encoding $\beta$-lactamase in a dose-dependent manner. Resistance develops due to the appearance of PBP2a and the production of $\beta$-lactamase, while our results suggested that DMC has an augmented bactericidal activity against MRSA due to its ability to disrupt the synthesis of PBP2a and the $\beta$-lactamase, thereby reversing the resistance of MRSA. In brief, DMC can be used as PBP2a inhibitor and $\beta$-lactamase inhibitor to reasonably explain the mechanism of reversing MRSA resistance.

\section{The inhibitory effect of DMC on the expression of SEA and related gene in MRSA}

As a representative virulence factor produced by MRSA, staphylococcal enterotoxin A (SEA) was detected to analyze whether the inhibitory mechanism of DMC on MRSA is related to $S$. aureus exotoxins. The secretion of SEA by ATCC 33591 exposed to sub-inhibitory concentrations of DMC was determined by western blotting analysis. Fig. 6a depicted that DMC reduced the expression of SEA in a dose-dependent manner compared with the untreated group and GEN treated group. This study also performed qRT-PCR analysis on the sea gene encoding SEA, and the results were consistent with western blot analysis. The sea gene was significantly inhibited dose-dependently after the addition of graded sub-inhibitory concentrations of DMC (Fig. 6b). The results indicated that the mechanism of DMC inhibiting invasive MRSA infection may be attributed to its blocking of $S$. aureus exotoxins synthesis.

\section{Discussion}

Based on the sensitivity to antibiotics, MRSA is defined as $S$. aureus with a minimum inhibitory concentration of oxacillin greater than or equal to $4 \mu \mathrm{g} / \mathrm{ml}$, while MSSA is sensitive to $\beta$-lactam antibiotics [39]. Due to the development of bacterial resistance, $\beta$-lactam antibiotics are no longer the first-line antimicrobial agent for the treatment of $S$. aureus infections. Practically, MRSA has become resistant to all available $\beta$-lactam antibiotics [40]. In view of the emergence and widespread dissemination of MRSA in the community, there is an urgent need to study a novel and potent therapeutic strategy of this serious public safety disease. In response to the difficult MRSA infection, the present study was designed to study the effect of DMC, a major phytochemical component originated from turmeric, on reversing the resistance of $S$. aureus to methicillin. Our drug susceptibility experiments on MRSA have shown that DMC has a certain effect on inhibiting the growth of bacteria. In addition, the synergistic antibacterial effect between DMC and antibiotic GEN is a valuable discovery, suggesting the medicinal potential of DMC to assist antibiotics in the treatment of MRSA infections. This study also explored the conditions for enhancing the antibacterial effect of DMC. The results showed that the inhibition of DMC on the growth of MRSA could be facilitated by reducing the metabolic level of bacteria with appropriate concentrations of ATP synthase inhibitors (DCCD and $\mathrm{NaN}_{3}$ ), which is conducive to further exploring the optimal antibacterial conditions for DMC.

There are two main mechanisms for MRSA to develop resistance: one is that even if PBPs are inhibited by binding to $\beta$-lactam antibiotics, the bacteria can still synthesize cell wall and maintain normal vitality 
due to the presence of the alternate PBP2a (encoded by $m e c A$ ) that is poorly bind to $\beta$-lactam antibiotics [41] ; the other is that bacteria produce $\beta$-lactamase (encoded by blaZ) to make the $\beta$-lactam antibiotics ineffective by hydrolyzing the $\beta$-lactam ring [42]. PBPs are enzymes that bind to and are inhibited by $\beta$ lactam antibiotics, which can synthesize the cell wall peptidoglycan on the outer surface of the cytoplasmic membrane [43]. MRSA can produce a 76KDa PBP2a, which is not available in MSSA. The function of PBP2a is equivalent to all the main functions of natural PBPs. The difference is that the ability of PBP2a to form the acyl-enzyme complexes with $\beta$-lactam antibiotics is reduced. Therefore, in the presence of such antibiotics, PBP2a can still complete the synthesis of bacterial cell walls, allowing bacteria to survive and develop drug resistance. According to the determination of PBP2a in this study, it can be found that DMC had a stronger inhibitory effect on the protein expression of PBP2a than GEN, implying the potential of DMC to be further developed as a PBP2a inhibitor.

The acquisition of the mecA gene encoding PBP2a is a major determinant of $\beta$-lactam resistance in MRSA strains. The $m e c A$ gene resides on a mobile genetic element designated staphylococcal cassette chromosome mec (SCCmec) [44]. The modular structure of SCCmec is composed of two essencial elements: the mec gene complex, comprising the $\beta$-lactam resistance determinant mecA and its regulators ( $m e c /$ and $m e c R 1$ ), and the ccrgene complex, containing cassette chromosome recombinase (ccr) genes responsible for cassette mobilization [45]. The transcription of mecA is regulated by the DNAbinding repressor Mecl and the transmembrane sensor/ transducer MecR1. When $\beta$-lactam antibiotics bind to the extracellular sensor domain of MecR1, MecR1 is activated [46]. Thus, the intracellular transducer domain dissociates the Mecl from mecA promoter region binding site and removes its repression of $m e c A$ [47]. Subsequently, $m e c A$ begins to transcript and produces a large amount of PBP2a, which makes bacteria resistant. The qRT-PCR results showed that GEN had no inhibitory effect on MRSA resistance genes, which explained the internal mechanism of antibiotics losing antibacterial effects. However, DMC substantially inhibited the gene expression of $m e c A$ and $m e c R 1$ at sub-inhibitory concentrations, indicating that the inhibition of PBP2a expression by DMC is related to its interference with the transcription of the mecoperon elements.

The $\beta$-lactamase is encoded by blaZ gene, and more than $90 \%$ of Staphylococcus isolates possess the blaZ gene and its regulatory sequences (blal and blaR1) [48]. The expression of blaZ gene, which encodes $\beta$-lactamase, is regulated by the sensor/ transducer protein BlaR1. Similar in function to MecR1, BlaR1 is a transmembrane sensor and signal transducing protein [49]. The extracellular sensor domain of BlaR1 can detect the presence of antibiotics in themilieu and transduce the signal to the cytoplasmic side of the membrane, degrading the gene repressor Blal [50]. The loss of Blal results in blaZ transcription and subsequent induction of $\beta$-lactam resistance. In fact, the transcription of mecA and $b l a Z$ is co-repressed by the two regulators $\mathrm{mecl}$ and b/al, which share $60 \%$ sequence homology and have similar functions [ 41 , $49,51]$. The qRT-PCR results of the bla operon element indicated that DMC hampered the transcription of blaZ and blaR1 at sub-inhibitory concentrations, and the 1/2MIC DMC showed a salient inhibitory effect, which once again proved the antibacterial mechanism that DMC prevented the survival of MRSA by inhibiting MRSA resistance genes. 
The staphylococcal enterotoxins (SEs) produced by S. aureus are considered to be bacterial superantigens that can induce cell proliferation, toxic shock syndrome and cytokine storm [52]. In addition, $\mathrm{SE}_{\mathrm{S}}$ has the potential to cause human staphylococcal gastroenteritis and food poisoning due to its resistance to gastrointestinal proteases and emetic activity [53]. SEA is the most common cause of Staphylococcus-related foodborne poisoning [54]. According to the measurement and analysis of SEA transcription and translation expression, DMC had significant inhibitory effects on the SEA gene and protein expression at sub-inhibitory concentrations dose-dependently, which could be inferred that DMC reduced the vitality of MRSA by suppressing the production of exotoxin induced by MRSA infection.

\section{Conclusions}

The present study endeavored to investigate the ability of DMC to suppress the pathogenic attack of MRSA. In order to achieve this, we designed a series of drug susceptibility tests to detect the inhibitory effect of DMC on different MRSA strains and the synergistic effect with $\beta$-lactam antibiotics, and detected several main resistance genes and virulence genes of MRSA to analyze the internal mechanism of DMC's inhibitory effect on MRSA. By analyzing the experimental results, we found that DMC showed a significant antibacterial effect and had a synergistic antibacterial effect with $\beta$-lactam antibiotic GEN. We explored the mechanism of DMC, and speculated that DMC compromised the vitality of MRSA by inhibiting the expression of PBP2a and related genes. In addition, the inhibitory effects of DMC on the expression of SEA and its related genes provided a distinct antibacterial mechanism. Our results suggest the potential of DMC to accelerate the healing of MRSA infections as a novel phytochemical compound. In the field of alternative medicine, DMC offers promises for the treatment of MRSA diseases. We plan to conduct further research on DMC to explore more physiological activities and antibacterial mechanisms of DMC against MRSA in the future.

\section{Declarations}

\section{Acknowledgements}

This study was supported by the Wonkwang University in 2021.

\section{Authors' contributions}

Conceptualization: QQL, OHK and DYK. Methodology: QQL, OHK and DYK. Investigation: QQL. Data curation: QQL. Writing-original draft preparation: QQL. Writing-review and editing: OHK and DYK. Supervision: OHK. Project administration: DYK. All authors have read and approved to the published version of the manuscript.

\section{Funding}

Not applicable. 
Availability of data and materials

The data used and analysed during the current study are available from the corresponding author on reasonable request.

\section{Ethics approval and consent to participate}

Not applicable.

\section{Consent for publication}

Not applicable.

\section{Competing interests}

The authors declared that they have no competing interests.

\section{Abbreviations}

DMC: Demethoxycurcumin; MRSA: methicillin-resistant Staphylococcus aureus; CFU: colony-forming unit; MIC: minimum inhibitory concentration; FICl: fractional inhibitory concentration index; PBP2a: Penicillinbinding protein 2a; SEA: staphylococcal enterotoxin A; SCCmec. staphylococcal cassette chromosome $m e c$, MTT $₫$ thiazolyl blue tetrazolium bromide $\triangle T X-100 \rrbracket$ triton X-100 $\otimes$ Tris: tris (hydroxymethy) aminomethane ACS reagent; DCCD: $\mathrm{N}, \mathrm{N}$-dicyclohexylcarbodiimide; $\mathrm{NaN}_{3}$ : sodium azide; OXA: oxacillin; AMP: ampicillin sodium salt; GEN: gentamicin sulfate.

\section{References}

1. Liang Y, Tu C, Tan C, El-Sayed Ahmed MAE, Dai M, Xia Y, et al. Antimicrobial resistance, virulence genes profiling and molecular relatedness of methicillin-resistant Staphylococcus aureus strains isolated from hospitalized patients in Guangdong Province, China. Infect Drug Resist. 2019;12:44759.

2. Tommasi R, Brown DG, Walkup GK, Manchester JI, Miller AA. ESKAPEing the labyrinth of antibacterial discovery. Nat Rev Drug Discov. 2015;14(8):529-42.

3. Savoldi A, Azzini AM, Baur D, Tacconelli E. Is there still a role for vancomycin in skin and soft-tissue infections? Curr Opin Infect Dis. 2018;31(2):120-30.

4. Xue L, Chen YY, Yan Z, Lu W, Wan D, Zhu H. Staphyloxanthin: a potential target for antivirulence therapy. Infect Drug Resist. 2019;12:2151-60.

5. Li S, Mou Q, Xu X, Qi S, PHM. L. Synergistic antibacterial activity between penicillenols and antibiotics against methicillin-resistant Staphylococcus aureus. R Soc Open Sci. 2018;5(5):172466.

6. El-Mokhtar MA, Hetta HF. Ambulance vehicles as a source of multidrug-resistant infections: a multicenter study in Assiut City, Egypt. Infect Drug Resist. 2018;11:587-94. 
7. Astley R, Miller FC, Mursalin MH, Coburn PS, Callegan MC. An Eye on Staphylococcus aureus Toxins: Roles in Ocular Damage and Inflammation. Toxins (Basel). 2019;11(6):356.

8. Stryjewski ME, Chambers HF. Skin and soft-tissue infections caused by community-acquired methicillin-resistant Staphylococcus aureus. Clin Infect Dis. 2008;46 Suppl 5:S368-77.

9. Belluzo BS, Abriata LA, Giannini E, Mihovilcevic D, Dal Peraro M, Llarrull LI. An experiment-informed signal transduction model for the role of the Staphylococcus aureus MecR1 protein in beta-lactam resistance. Sci Rep. 2019;9(1):19558.

10. Khan AU, Ali A, Danishuddin, Srivastava G, Sharma A. Potential inhibitors designed against NDM-1 type metallo-beta-lactamases: an attempt to enhance efficacies of antibiotics against multi-drugresistant bacteria. Sci Rep. 2017;7(1):9207.

11. Lai CC, Chen CC, Lu YC, Lin TP, Chuang YC, Tang HJ. Appropriate composites of cefoperazonesulbactam against multidrug-resistant organisms. Infect Drug Resist. 2018;11:1441-5.

12. Zhang H, Ma G, Zhu Y, Zeng L, Ahmad A, Wang C, et al. Active-Site Conformational Fluctuations Promote the Enzymatic Activity of NDM-1. Antimicrob Agents Chemother. 2018;62(11):e01579-18.

13. Huang HH, Chen PY, Hu RM, Lin YT, Li LH, Yang TC. Impacts of L1 Promoter Variation and L2 Clavulanate Susceptibility on Ticarcillin-Clavulanate Susceptibility of Stenotrophomonas maltophilia. Antimicrob Agents Chemother. 2018;62(11):e01222-18.

14. Cabeen MT, Jacobs-Wagner C. Bacterial cell shape. Nat Rev Microbiol. 2005;3(8):601-10.

15. Lee CW, Tseng YH, Deng FS, Lin JW, Tseng YH, Weng SF. Contribution of Phe-7 to Tat-dependent export of beta-lactamase in Xanthomonas campestris. Antimicrob Agents Chemother. 2012;56(7):3597-602.

16. Cheong WL, Tsang MS, So PK, Chung WH, Leung YC, Chan PH. Fluorescent TEM-1 beta-lactamase with wild-type activity as a rapid drug sensor for in vitro drug screening. Biosci Rep. 2014;34(5):e00136.

17. Winkler ML, Papp-Wallace KM, Bonomo RA. Activity of ceftazidime/avibactam against isogenic strains of Escherichia coli containing KPC and SHV beta-lactamases with single amino acid substitutions in the Omega-loop. J Antimicrob Chemother. 2015;70(8):2279-86.

18. Vandavasi VG, Langan PS, Weiss KL, Parks JM, Cooper JB, Ginell SL, et al. Active-Site Protonation States in an Acyl-Enzyme Intermediate of a Class A beta-Lactamase with a Monobactam Substrate. Antimicrob Agents Chemother. 2017;61(1):e01636-16.

19. Monteiro JM, Covas G, Rausch D, Filipe SR, Schneider T, Sahl HG, et al. The pentaglycine bridges of Staphylococcus aureus peptidoglycan are essential for cell integrity. Sci Rep. 2019;9(1):5010.

20. Tavares DA, Sa-Leao R, Miragaia M, de Lencastre H. Large screening of CA-MRSA among Staphylococcus aureus colonizing healthy young children living in two areas (urban and rural) of Portugal. BMC Infect Dis. 2010;10:110.

21. Larsen J, Andersen PS, Winstel V, Peschel A. Staphylococcus aureus CC395 harbours a novel composite staphylococcal cassette chromosome mec element. J Antimicrob Chemother. 2017;72(4):1002-5. 
22. Thalso-Madsen I, Torrubia FR, Xu L, Petersen A, Jensen C, Frees D. The Sle1 Cell Wall Amidase Is Essential for beta-Lactam Resistance in Community-Acquired Methicillin-Resistant Staphylococcus aureus USA300. Antimicrob Agents Chemother. 2019;64(1):e01931-19.

23. Mwangi MM, Kim C, Chung M, Tsai J, Vijayadamodar G, Benitez M, et al. Whole-genome sequencing reveals a link between beta-lactam resistance and synthetases of the alarmone (p)ppGpp in Staphylococcus aureus. Microb Drug Resist. 2013;19(3):153-9.

24. Lee H, Yoon EJ, Kim D, Kim JW, Lee KJ, Kim HS, et al. Ceftaroline Resistance by Clone-Specific Polymorphism in Penicillin-Binding Protein 2a of Methicillin-Resistant Staphylococcus aureus. Antimicrob Agents Chemother. 2018;62(9):e00485-18.

25. Hou Z, Zhou Y, Wang H, Bai H, Meng J, Xue X, et al. Co-blockade of mecR1/blaR1 signal pathway to restore antibiotic susceptibility in clinical isolates of methicillin-resistant Staphylococcus aureus. Arch Med Sci. 2011;7(3):414-22.

26. Yang S, Zhang J, Yan Y, Yang M, Li C, Li J, et al. Network Pharmacology-Based Strategy to Investigate the Pharmacologic Mechanisms of Atractylodes macrocephala Koidz. for the Treatment of Chronic Gastritis. Front Pharmacol. 2019;10:1629.

27. Choi Y, Ban I, Lee H, Baik MY, Kim W. Puffing as a Novel Process to Enhance the Antioxidant and AntiInflammatory Properties of Curcuma longa L. (Turmeric). Antioxidants (Basel). 2019;8(11):506.

28. Mapoung S, Suzuki S, Fuji S, Naiki-Ito A, Kato H, Yodkeeree S, et al. Cyclohexanone curcumin analogs inhibit the progression of castration-resistant prostate cancer in vitro and in vivo. Cancer Sci. 2019;110(2):596-607.

29. Hay E, Lucariello A, Contieri M, Esposito T, De Luca A, Guerra G, et al. Therapeutic effects of turmeric in several diseases: An overview. Chemico-Biological Interactions. 2019;310:108729.

30. Chien MH, Yang WE, Yang YC, Ku CC, Lee WJ, Tsai MY, et al. Dual Targeting of the p38 MAPK-HO-1 Axis and cIAP1/XIAP by Demethoxycurcumin Triggers Caspase-Mediated Apoptotic Cell Death in Oral Squamous Cell Carcinoma Cells. Cancers (Basel). 2020;12(3):703.

31. Hatamipour M, Ramezani M, Tabassi SAS, Johnston TP, Ramezani M, Sahebkar A. Demethoxycurcumin: A naturally occurring curcumin analogue with antitumor properties. J Cell Physiol. 2018;233(12):9247-60.

32. Hatamipour M, Ramezani M, Tabassi SAS, Johnston TP, Sahebkar A. Demethoxycurcumin: A naturally occurring curcumin analogue for treating non-cancerous diseases. J Cell Physiol. 2019;234(11):19320-30.

33. Mun SH, Kang OH, Joung DK, Kim SB, Choi JG, Shin DW, et al. In vitro anti-MRSA activity of carvone with gentamicin. Exp Ther Med. 2014;7(4):891-6.

34. Luna BM, Ershova K, Yan J, Ulhaq A, Nielsen TB, Hsieh S, et al. Adjunctive transferrin to reduce the emergence of antibiotic resistance in Gram-negative bacteria. J Antimicrob Chemother. 2019;74(9):2631-9.

35. Lee YS, Han SH, Lee SH, Kim YG, Park CB, Kang OH, et al. The mechanism of antibacterial activity of tetrandrine against Staphylococcus aureus. Foodborne Pathog Dis. 2012;9(8):686-91. 
36. Zhou T, Li Z, Kang OH, Mun SH, Seo YS, Kong R, et al. Antimicrobial activity and synergism of ursolic acid 3-0-alpha-L-arabinopyranoside with oxacillin against methicillin-resistant Staphylococcus aureus. Int J Mol Med. 2017;40(4):1285-93.

37. Toei M, Noji H. Single-molecule analysis of FOF1-ATP synthase inhibited by N,Ndicyclohexylcarbodiimide. J Biol Chem. 2013;288(36):25717-26.

38. Joung DK, Lee YS, Han SH, Lee SW, Cha SW, Mun SH, et al. Potentiating activity of luteolin on membrane permeabilizing agent and ATPase inhibitor against methicillin-resistant Staphylococcus aureus. Asian Pac J Trop Med. 2016;9(1):19-22.

39. Zhang Z, Chen M, Yu Y, Liu B, Liu Y. In Vitro Activity Of Ceftaroline And Comparators Against Staphylococcus aureus Isolates: Results From 6 Years Of The ATLAS Program (2012 To 2017). Infect Drug Resist. 2019;12:3349-58.

40. Meng J, Da F, Ma X, Wang N, Wang Y, Zhang H, et al. Antisense growth inhibition of methicillinresistant Staphylococcus aureus by locked nucleic acid conjugated with cell-penetrating peptide as a novel FtsZ inhibitor. Antimicrob Agents Chemother. 2015;59(2):914-22.

41. Safo MK, Zhao Q, Ko TP, Musayev FN, Robinson H, Scarsdale N, et al. Crystal structures of the Blal repressor from Staphylococcus aureus and its complex with DNA: insights into transcriptional regulation of the bla and mec operons. J Bacteriol. 2005;187(5):1833-44.

42. Llarrull LI, Toth M, Champion MM, Mobashery S. Activation of BlaR1 protein of methicillin-resistant Staphylococcus aureus, its proteolytic processing, and recovery from induction of resistance. J Biol Chem. 2011;286(44):38148-58.

43. Matsuda $Y$, Itaya $\mathrm{H}$, Kitahara $\mathrm{Y}$, Theresia NM, Kutukova EA, Yomantas YA, et al. Double mutation of cell wall proteins CspB and PBP1a increases secretion of the antibody Fab fragment from Corynebacterium glutamicum. Microb Cell Fact. 2014;13(1):56.

44. Dar JA, Thoker MA, Khan JA, Ali A, Khan MA, Rizwan M, et al. Molecular epidemiology of clinical and carrier strains of methicillin resistant Staphylococcus aureus (MRSA) in the hospital settings of north India. Ann Clin Microbiol Antimicrob. 2006;5:22.

45. Milheirico $C$, de Lencastre $H$, Tomasz A. Full-Genome Sequencing Identifies in the Genetic Background Several Determinants That Modulate the Resistance Phenotype in Methicillin-Resistant Staphylococcus aureus Strains Carrying the Novel mecC Gene. Antimicrob Agents Chemother. 2017;61(3):e02500-16.

46. Hiramatsu K. molecular evolution of MRSA. Microbiol Immunol. 1995;39(8):531-43.

47. Suzuki E, Kuwahara-Arai K, Richardson JF, Hiramatsu K. Distribution of mec regulator genes in methicillin-resistant Staphylococcus clinical strains. Antimicrob Agents Chemother. 1993;37(6):121926.

48. Rosato AE, Kreiswirth BN, Craig WA, Eisner W, Climo MW, Archer GL. mecA-blaZ corepressors in clinical Staphylococcus aureus isolates. Antimicrob Agents Chemother. 2003;47(4):1460-3.

49. Black CC, Eberlein LC, Solyman SM, Wilkes RP, Hartmann FA, Rohrbach BW, et al. The role of mecA and blaZ regulatory elements in mecA expression by regional clones of methicillin-resistant 
Staphylococcus pseudintermedius. Vet Microbiol. 2011;151(3-4):345-53.

50. Speri E, Fishovitz J, Mobashery S. Structure-activity relationship of the cinnamamide family of antibiotic potentiators for methicillin-resistant Staphylococcus aureus (MRSA). Medchemcomm. 2018;9(12):2008-16.

51. Klitgaard JK, Skov MN, Kallipolitis BH, Kolmos HJ. Reversal of methicillin resistance in Staphylococcus aureus by thioridazine. J Antimicrob Chemother. 2008;62(6):1215-21.

52. Huang TM, Chou CC. Methicillin-sensitive and methicillin-resistant Staphylococcus aureus strains and their toxin genes in the nostrils of dogs and workers at an animal shelter. J Appl Microbiol. 2019;126(6):1899-909.

53. Koziel J, Chmiest D, Bryzek D, Kmiecik K, Mizgalska D, Maciag-Gudowska A, et al. The Janus face of alpha-toxin: a potent mediator of cytoprotection in staphylococci-infected macrophages. J Innate Immun. 2015;7(2):187-98.

54. Pinchuk IV, Beswick EJ, Reyes VE. Staphylococcal enterotoxins. Toxins (Basel). 2010;2(8):2177-97.

\section{Figures}

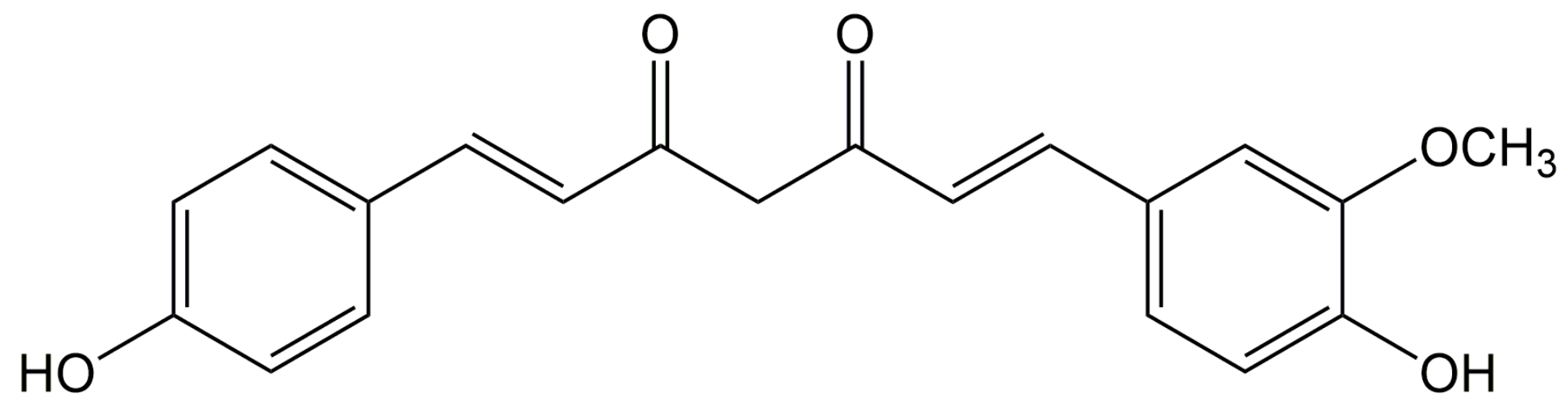

\section{Figure 1}

The chemical structure of demethoxycurcumin (DMC)

a

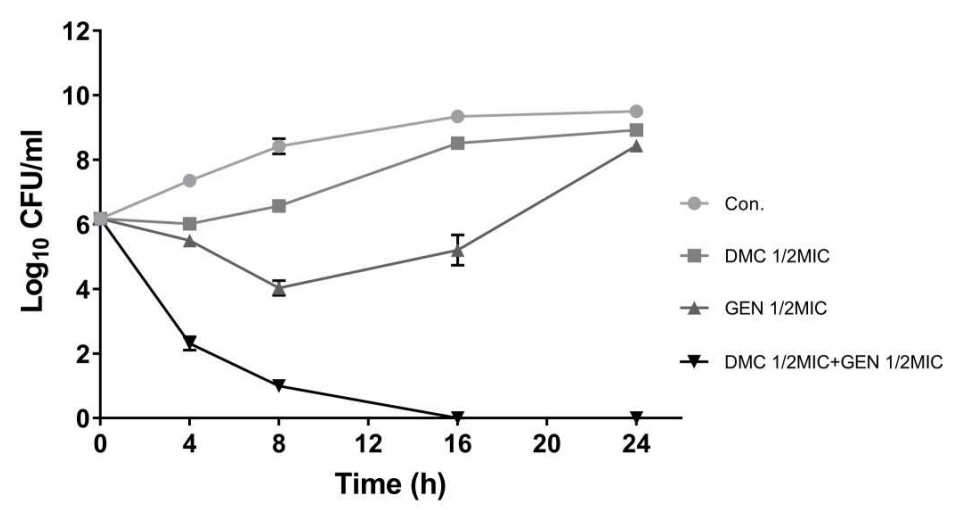

b

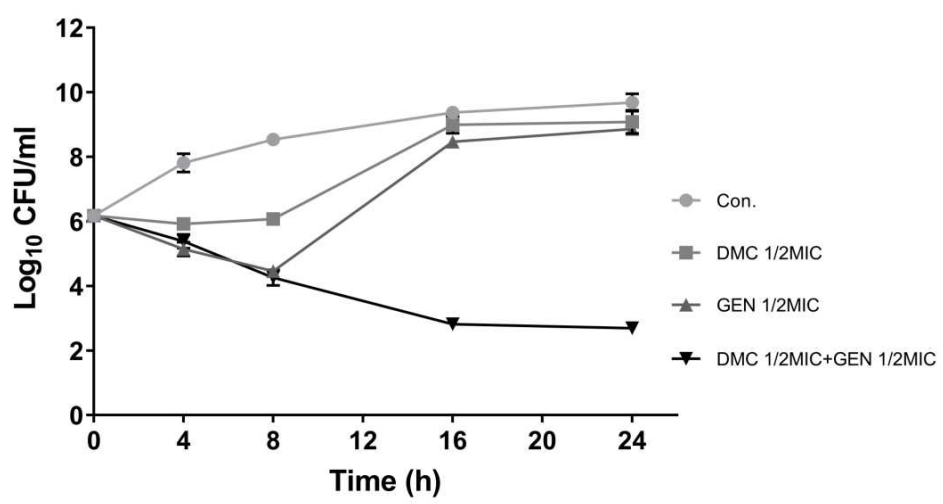

Figure 2 
Time-kill curves of DMC and gentamicin (GEN) alone and in combinations against MRSA (a. MRSA ATCC 33591; b. MRSA DPS-2)

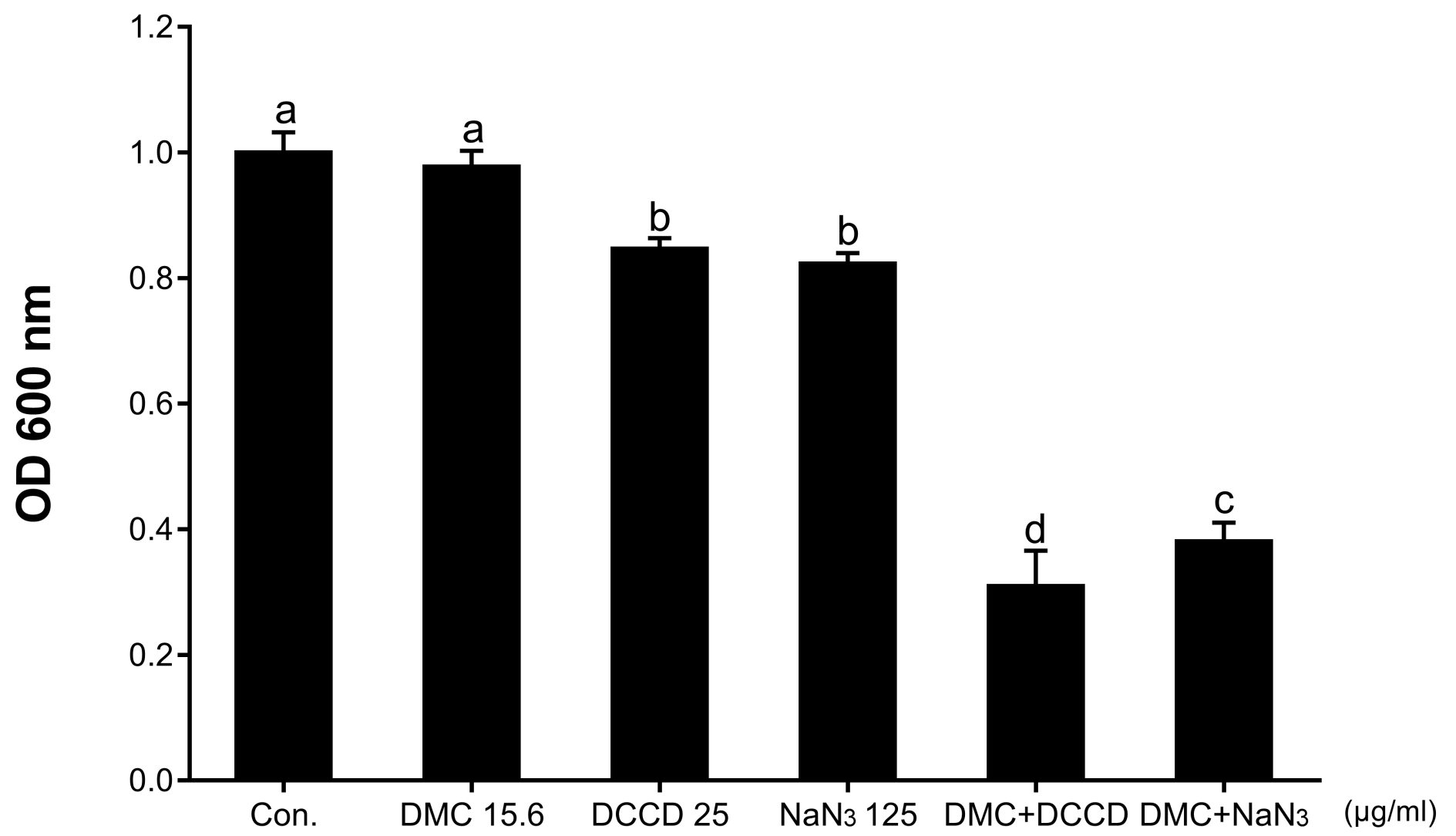

Figure 3

The effect of the ATP synthase inhibitors, DCCD $(25 \mu \mathrm{g} / \mathrm{ml})$ and NaN3 $(125 \mu \mathrm{g} / \mathrm{ml})$, on the susceptibility of MRSA strain ATCC 33591 to DMC treatment $(15.6 \mu \mathrm{g} / \mathrm{ml})$. The data are means \pm SD of triplicate determinations. Different letters in each bars indicate significant statistical differences between treatments $(p<0.05)$ 
Lane

GEN

DMC

PBP2a

1

2

3

4

5

3.9

$(\mu \mathrm{g} / \mathrm{ml})$

7.8

15.6

31.25

$-$

$(\mu \mathrm{g} / \mathrm{ml})$

GAPDH

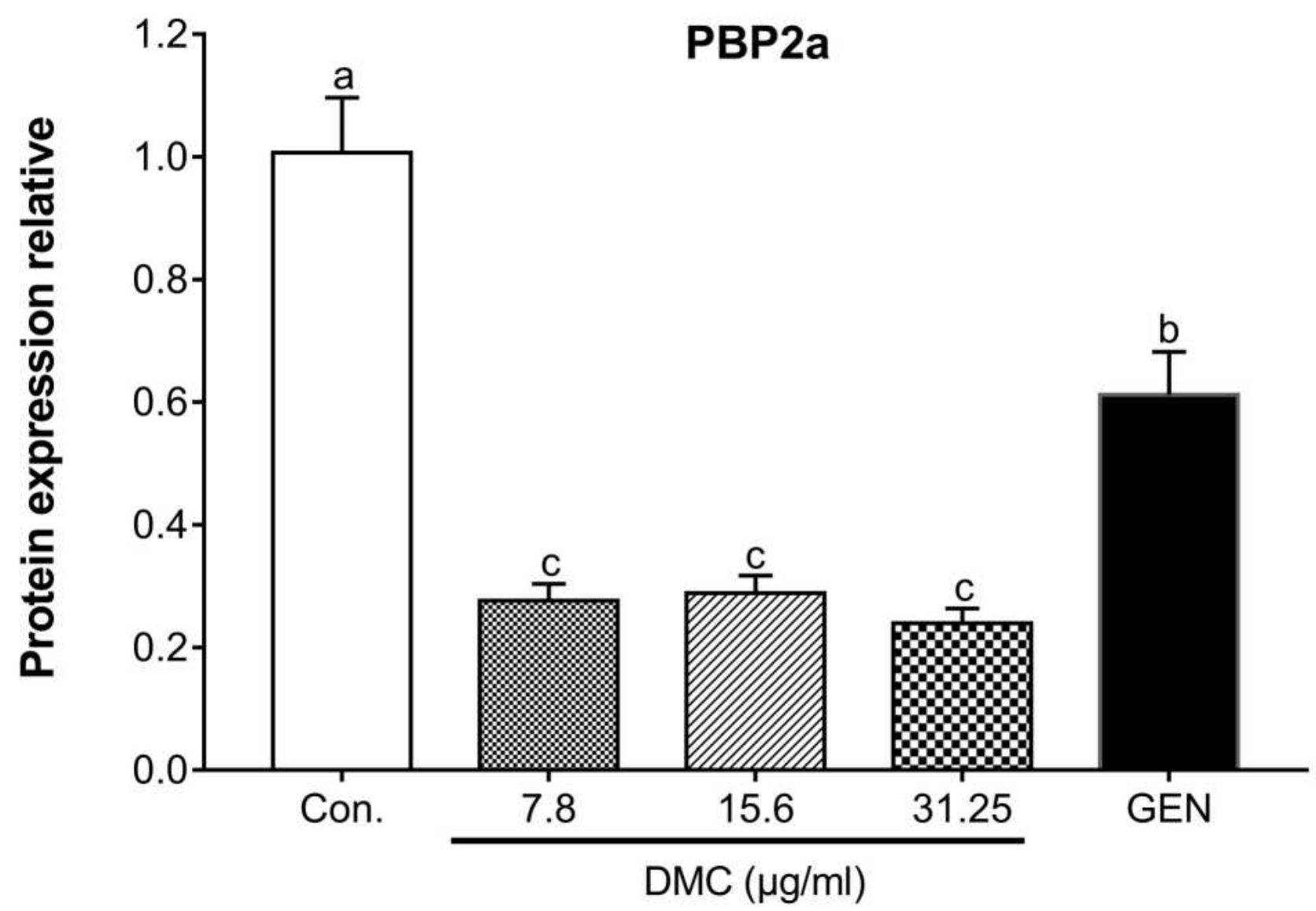

Figure 4

The effect of DMC and GEN on the expression of PBP2a in MRSA strain ATCC 33591, as analyzed by western blot. Loading differences were normalized by anti-GAPDH antibody. 
a

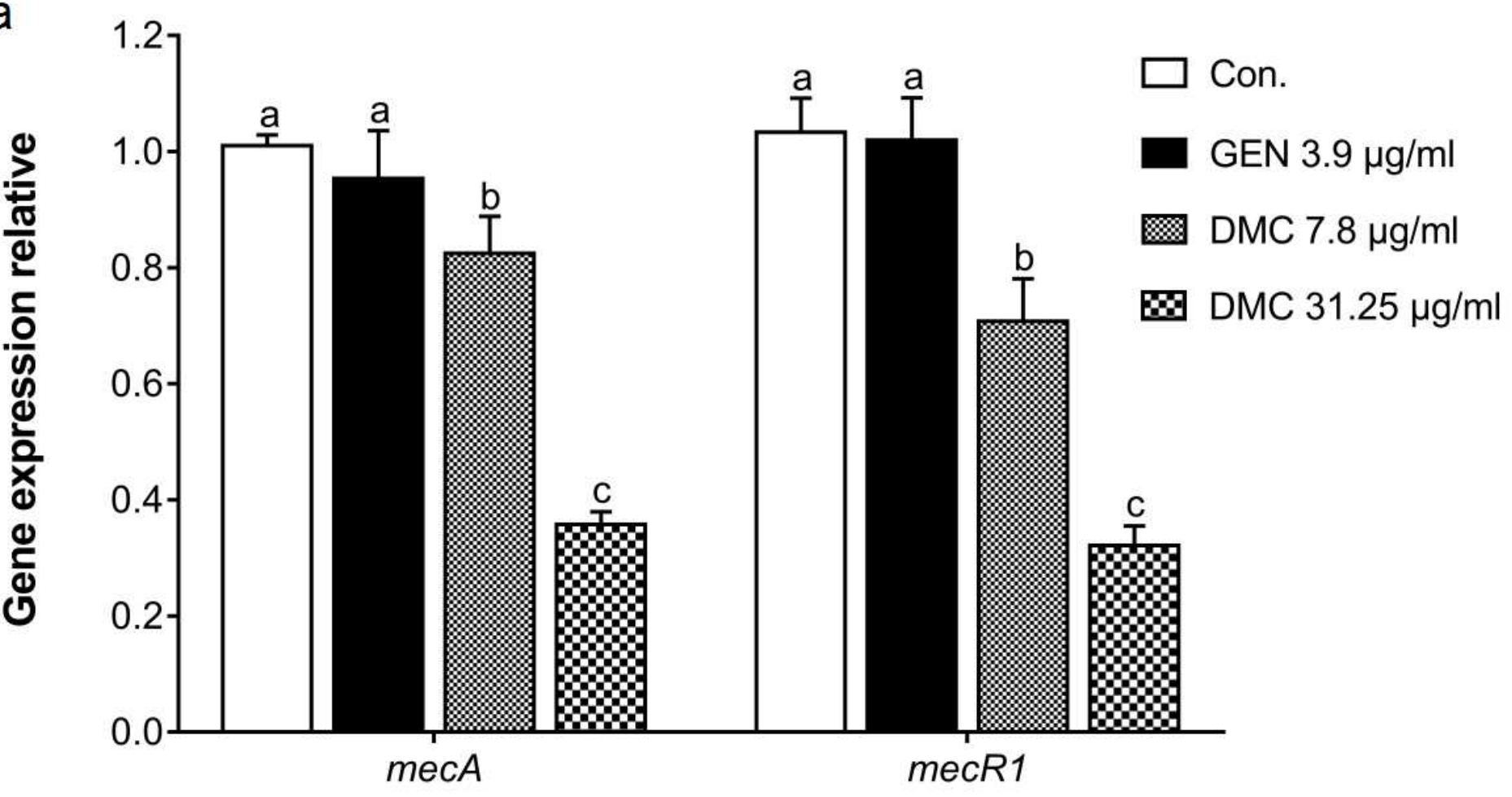

b

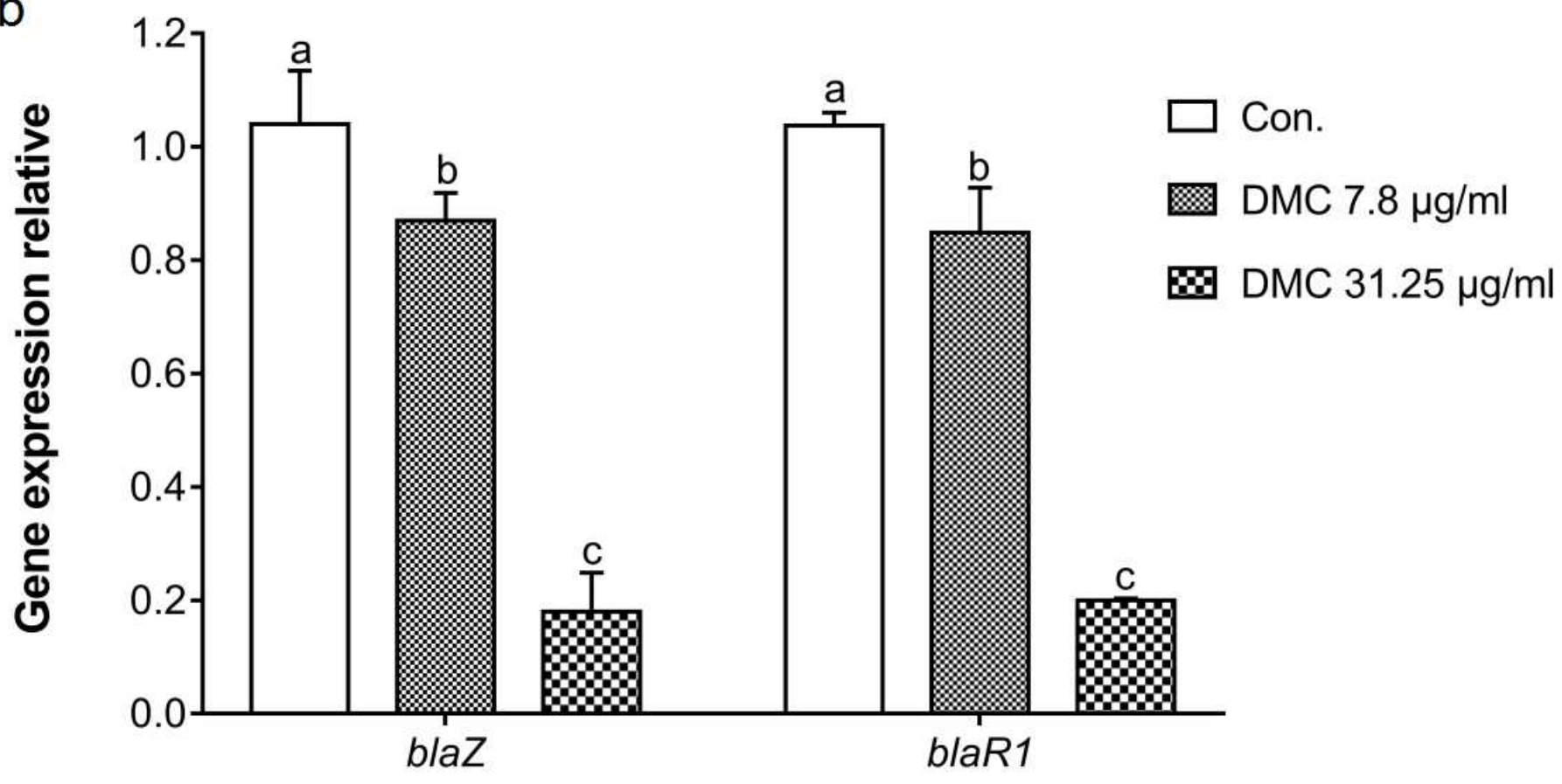

Figure 5

The effect of DMC and GEN on the mRNA expression of mec operon (a) and bla operon (b), as analyzed by qRT-PCR. ATCC 33591 were treated with serial dilution of DMC $(7.8 \mu \mathrm{g} / \mathrm{ml}$ and $31.25 \mu \mathrm{g} / \mathrm{ml})$ and GEN $(3.9 \mu \mathrm{g} / \mathrm{ml})$. The data are means \pm SD of triplicate determinations. Different letters in each bars indicate significant statistical differences between treatments $(p<0.05)$ 
a
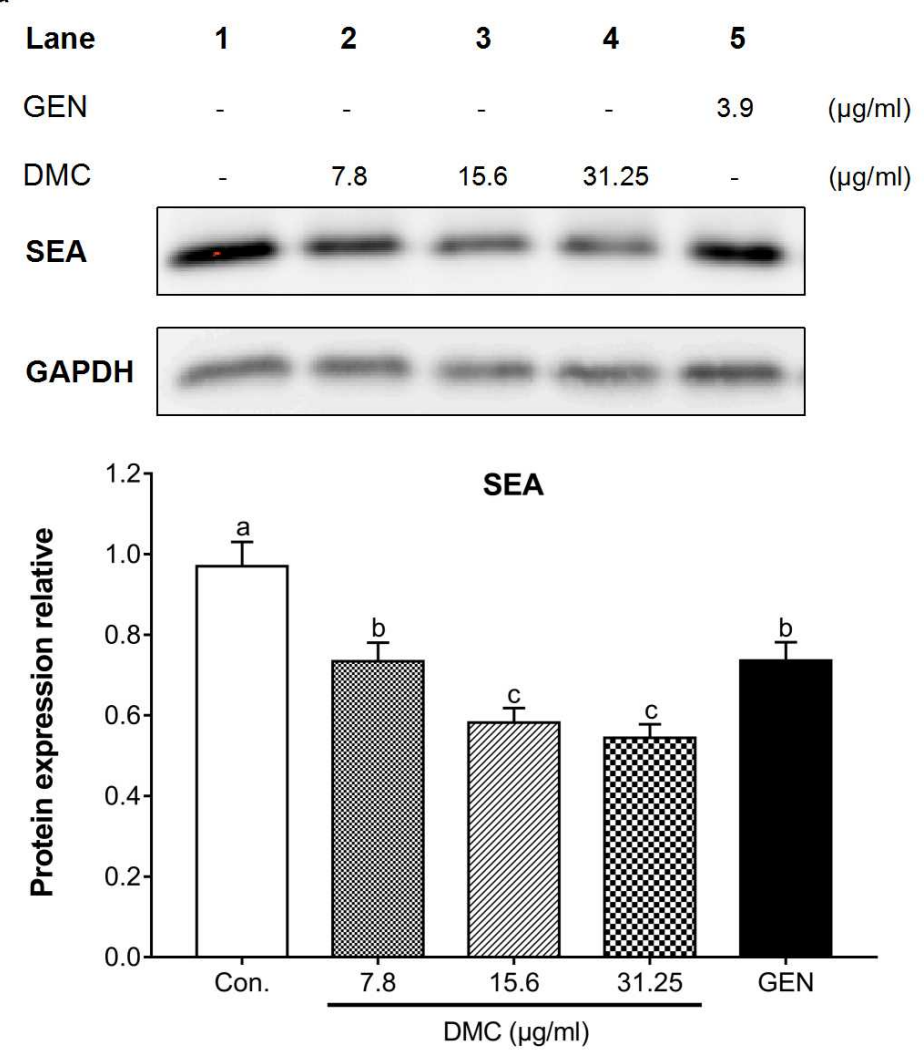

b

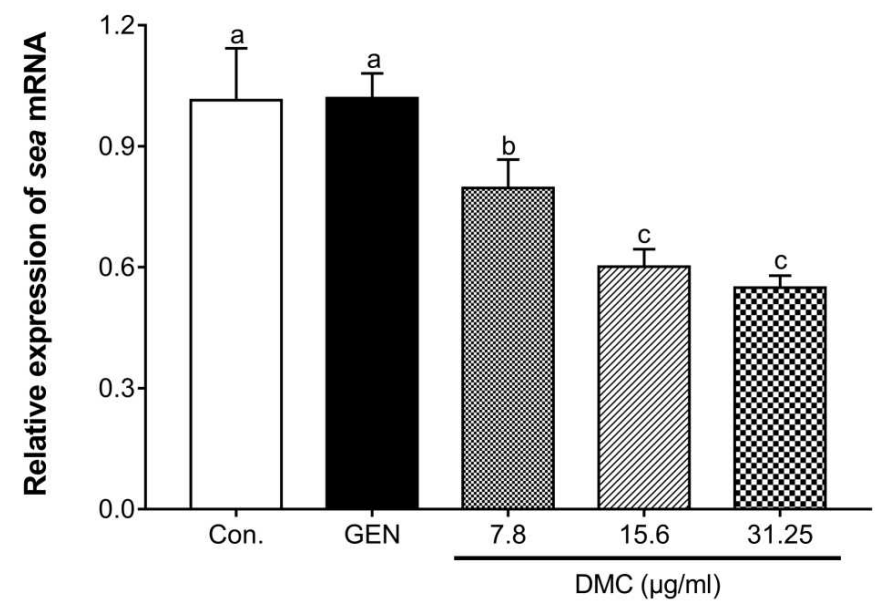

Figure 6

The effect of DMC on the protein (a) and mRNA (b) expression of SEA, as analyzed by western blot and qRT-PCR. ATCC 33591 were treated with serial dilution of DMC $(7.8 \mu \mathrm{g} / \mathrm{ml}, 15.6 \mu \mathrm{g} / \mathrm{ml}$ and $31.25 \mu \mathrm{g} / \mathrm{ml})$ and GEN $(3.9 \mu \mathrm{g} / \mathrm{ml})$. The data are means \pm SD of triplicate determinations. Different letters in each bars indicate significant statistical differences between treatments $(p<0.05)$ 